\title{
Single-step extraction-esterification process to produce biodiesel from palm oil mill effluent (POME) using microwave heating: a circular economy approach to making use of a difficult waste product
}

\author{
Elis Davies ${ }^{1} \cdot$ Pauline Deutz $^{1} \cdot$ Sharif H. Zein ${ }^{1}$ \\ Received: 1 April 2020 / Revised: 22 June 2020 / Accepted: 1 July 2020 / Published online: 14 July 2020 \\ (C) The Author(s) 2020
}

\begin{abstract}
This investigation explores single-step biodiesel synthesis using palm oil mill effluent (POME) as a feedstock. Normally considered a waste product from the extraction process of palm oil, POME treatment is difficult and can cause significant environmental pollution if discharged directly into watercourses. Fatty acids (FAs) present in POME were extracted and subsequently esterified in situ to FA methyl esters (FAME) suitable for use as biodiesel. The process of simultaneous extraction and esterification was performed under microwave irradiation in a sealed vessel, which has been shown to reduce both time of reaction and energy use considerably in other reactions. The simultaneous extraction and esterification result in an $89 \%$ yield of biodiesel from the available FAs in the POME solids. The facile separation of biodiesel products from the reaction mixture augments the process and here presented is a potential route to making economic use of this difficult feedstock.
\end{abstract}

Keywords Biodiesel $\cdot$ Palm oil mill effluent $\cdot$ Microwave $\cdot$ Esterification $\cdot$ Circular economy

\section{Introduction}

The circular economy (CE), whereby resources are kept in economic circulation for as long as possible and waste minimized, is currently a hotly debated concept in academic and policy circles. CE initiatives, such as recovery, recycling and re-use, are seen as promoting carbon emissions reductions, resource security and economic competitiveness [1]. Successfully implemented, CE approaches could make a substantial contribution to the United Nations' Sustainable Development Goals, though that is presently largely a matter for speculation $[2,3]$. Cognisant of the wider social and economic context, this research tackles a specific, currently

Elis Davies

e.davies@2011.hull.ac.uk

Pauline Deutz

p.deutz@hull.ac.uk

Sharif H. Zein

s.h.zein@hull.ac.uk

1 University of Hull, Hull, UK environmentally problematic, residue stream of an industry of significance to a number of countries in the Global South. Approaches to the CE, as with the earlier concepts on which it builds, need to take into account geographic context industries and nations start with certain circumstances (e.g., dependence on particular industries), which may more constructively be adapted rather than abandoned [4].

Since its introduction in the early 1900s from West Africa, the oil palm Elaeis guineensis has become the most valuable crop for countries in South East Asia. By 2007, palm oil had become the most consumed oil globally unseating soybean oil $[5,6]$. Oil palm production has attracted much criticism on environmental grounds, with attention focusing on the prevention of further deforestation. There has also been research and policy activity into how to make existing production more efficient and less polluting. The Malaysia government, for example, introduced regulations mandating the capture of carbon emissions from POME that are typically left to microbial action in ponds open to the atmosphere [7]. Palm oil has helped lift Malaysia's economy to the ranks of upper-middle income countries, and the programme of increasing efficiency of production is part of the Malaysian government's drive to reach high-income status (aiming at 2020). An existing 
technology for managing POME is anaerobic digestion, which implies decomposition in a controlled environment (minimizing leakages to air or water) and generation of energy from the methane. This paper, however, pursues a higher value and more mobile form of energy, i.e., biodiesel. Pollution from the extraction of palm oil is mainly found in the waste water that is created; this is primarily the discharge from the sterilization process and separator hydrocyclones known as palm oil mill effluent (POME) $[8,9]$. The harmful characteristics of POME can be summarized by its low $\mathrm{pH}$ and exceptionally high chemical and biological oxygen demand (COD and BOD respectively) that cause significant damage to watercourses if directly discharged. [10-12] During the rapid expansion of the Malaysian palm oil industry, which has seen the number of palm oil mills rise sharply from 10 in 1960 to 410 in 2008, there has also been a corresponding increase in the quantity of POME produced [13]. It is estimated that for every tonne of crude palm oil produced, around $3 \mathrm{t}$ of POME is also created leading to large volumes requiring treatment. For example, in 200943.8 million cubic metres of POME was generated in Malaysia alone [9, 12, 14, 15].

However, due to the oil content present in POME, there is emerging interest in the utilization of this material as a feedstock for biodiesel production. Biodiesel is a synthetic fuel commonly defined as the alkyl esters of long chain FAs sourced from organic biomass such as vegetable oils or animal fats [16]. Biodiesel produced from waste products has become a focus of research in contemporary times. This approach offers several key advantages; chief among which is the reduction in competition for raw materials, e.g., food [7, 17-19]. In addition, waste products are generally abundant, cheap and potentially difficult to dispose of currently; therefore, any potential use is advantageous to both the producer of the waste and the environment as a whole $[20,21]$. Even when the considering the low oil content of POME, the potential biodiesel yield could be significant. The use of POME as a biodiesel feedstock is a relatively new area with few publications at the time of writing, mainly concerning biological conversion methods [22, 23].

The difficulties of using POME include the relatively low oil concentration in addition to the complex mix of surface-active particles as well as the variable composition of the POME from mill to mill. One potential avenue for the treatment of POME is the field of microwave chemistry. Since the seminal paper in 1986 by Gedye et al. microwave processing has been successfully applied to many organic chemical reactions, with reports of high yields and very short processing times the primary advantages [24, 25]. As well as numerous applications in the field of organic chemistry, microwave technology has been successfully applied to process of solvent extraction, known as microwave assisted extraction (MAE). First explored by Ganzler et al. MAE makes use of the direct heating of the sample/solvent with microwave radiation to enhance extraction yields and lower both extraction times and energy usage [26-28]. The single step, single vessel extraction and esterification reactions being performed in this investigation represent a novel integrated method for the direct conversion of POME to biodiesel. By combining the advantages microwave technology has in both material extraction and organic reactions to the difficult feedstock that is POME, this investigation has increased the economic viability of waste treatment, thus incentivizing the removal of polluting FAs from the waste stream.

\section{Methods and materials}

Raw POME was sourced from Langkon Palm Oil Mill in Sabah, Malaysia, and stored in sealed containers for transportation and storage. Methanol, heptane, magnesium sulphate and sulphuric acid were obtained from VWR chemicals.

For the following experiments raw POME was used. Samples used for experimentation were taken from an agitated sample, representing freshly discharged, unsettled POME.

\subsection{Extraction and esterification of fatty acids present in POME}

About $15 \mathrm{ml}$ of POME was centrifuged at RCF 3.0 (4400 RPM) in an Eppendorf 5702 centrifuge for $30 \mathrm{~min}$. The supernatant was put aside, and the pellet was transferred to a temperature-controlled microwave vessel. The organic solvent and acid catalyst were then added; the vessel was sealed and placed in a Milestone Ethos EX microwave. Microwave heating was performed for $15 \mathrm{~min}$ at a constant temperature of $150{ }^{\circ} \mathrm{C}$. After the heating period the system was allowed to cool to room temperature. Once cooled the reaction mixture was transferred to a separating funnel and the organic layer was removed. The organic layer was diluted 1:1 with BSTFA + TMCS (99:1) derivatization agent, and concentrations of FAs and methyl esters (MEs) were analysed by GC-MS performed on a Hewlett Packard 6890 Plus fitted with a Thames Restek Rxi-17Sil MS moderate polarity column.

\subsection{Determination of the initial oil content of the POME sample}

For the purpose of the evaluation of microwave reactions, the oil content of the raw POME sample was initially determined. A modified extraction procedure as set out in ISO standard 9377-2 was performed in addition to GC-MS quantification of the extracted materials. Briefly, $50 \mathrm{ml}$ of POME was acidified to $\mathrm{pH} 2$, sealed in a vessel and stirred with the heptane extraction solvent for $30 \mathrm{~min}$. Afterwards, magnesium sulphate was added and the organic layer was removed. A sample of the organic layer was diluted 1:1 with BSTFA + TMCS (99:1) derivatization agent and concentrations of FAs quantified by GC-MS as above. 


\subsection{Water content of POME solids}

An Ohaus MB23 moisture content determination apparatus was used to accurately quantify the water content in the centrifuged POME used for biodiesel production experiments. A sample of centrifuged POME (around $1.0 \mathrm{~g}$ ) was placed onto a pre-weighed aluminium disc and placed onto the cradle of the MB23. The apparatus was activated, and the device tracked the mass of the sample as the temperature is increased by an infra-red heating element present above the sample disc. After no additional change in temperature is recorded, the system reports the difference in mass between the initial and final reading as a percentage of the initial mass. This is equivalent to the mass lost as water vapour from the sample.

\subsection{Statistical optimization methods}

The experimental condition matrix was designed using analysis of variance (ANOVA) software Design Expert 11 using response surface methodology (RSM) coupled with central composite design (CCD) to form a of this experimental design strategy that enables the embodiment of advantages of performing a specific number of experiments from otherwise performing unnecessary experiments, whilst fully considering the multivariate nature of any novel process parameters (factors), as well as consideration of the definite interactions between parameters (factors: volume of methanol, $\mathrm{H}_{2} \mathrm{SO}_{4}$ concentration, stirring), and their impact on the response yield (ME and FA concentrations).

\section{Results and discussion}

\subsection{Initial fatty acid concentration in POME}

The principle components identified in the solvent extraction of raw untreated POME were FAs, principally palmitic acid and to a lesser extent oleic acids and isomers thereof. Trace amounts of other FAs were detected as expected. For easy comparison the concentration of palmitic acid was used to evaluate the extraction efficiency and the esterification yield in this investigation. The concentration of palmitic acid in the raw pome sample was found to be $1.16 \mathrm{mg} / \mathrm{ml}$. All extractions and reactions will be compared with this reference value for the purpose of determining yield and conversion to biodiesel. Figure 1 represents the make-up of oil extracted from raw POME according to the ISO method detailed in the previous section. The first and largest peak present at a retention time (RT) of $3.1 \mathrm{~min}$ is palmitic acid, unsurprisingly the most abundant component of POME. The peak at RT $3.65 \mathrm{~min}$ is the internal standard, docosane, used for accurate quantitation. The series of peaks between 4.1 and $4.4 \mathrm{~min}$ RT are the various $\mathrm{C} 18$ fatty acids, including primarily oleic acid itself (cis-9-octadecenoic acid) as well as linoleic acid (9,12-octadecadienoic acid) as well as the saturated stearic acid (octadecanoic acid). The solvent extraction produces a remarkably clean extraction profile with only fatty acids being extracted.

\subsection{Water content of POME solids}

The water content of the POME sample was determined The POME analysed was centrifuged to be representative of the POME used in the biodiesel production experiments. The water content of the centrifuged POME was found to be $97.9 \pm$ $0.3 \%$. Even after centrifugation, the water content of the centrifuged POME solids is still high, with almost the entire mass of the sample being water. Despite this, the appearance of the POME is that of a fibrous paste. The temperature of the water determination apparatus was set at a mild $120{ }^{\circ} \mathrm{C}$ in order to prevent the volatilization of any fatty acids or other organics that could detrimentally affect the accuracy of the water content determination.

\subsection{Comparison between microwave and bench heating}

In order to assess the rate enhancement possible when working with microwave heating system, 3 identical reaction mixtures containing pure palmitic acid were heated with methanol and a $\mathrm{H}_{2} \mathrm{SO}_{4}$ catalyst. The first reaction was performed under reflux heating, whereas the second
Fig. 1 Chromatogram of derivatized POME components as extracted according to the procedure above and analysed by GC-MS

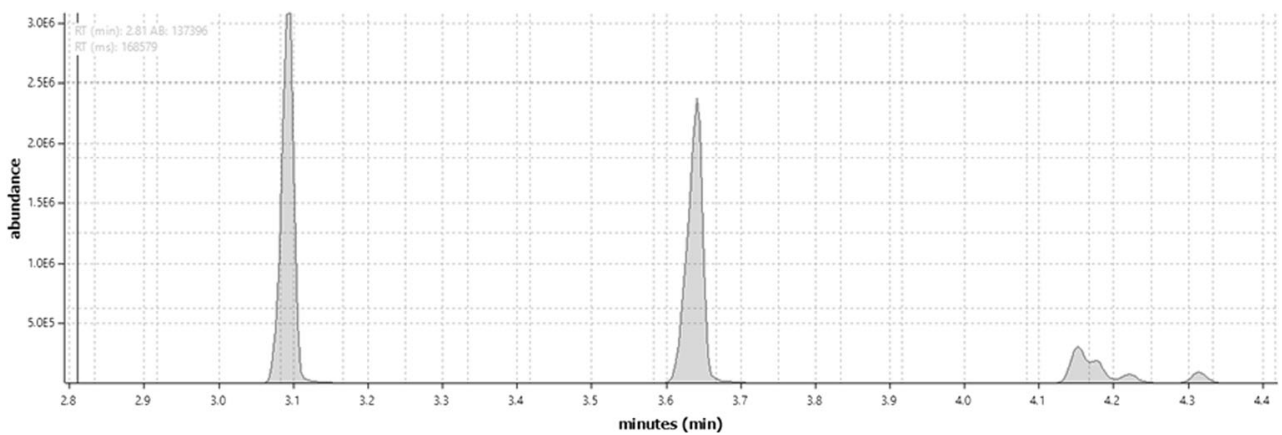


Fig. 2 FAME concentration of reactions comparing microwave and bench heating

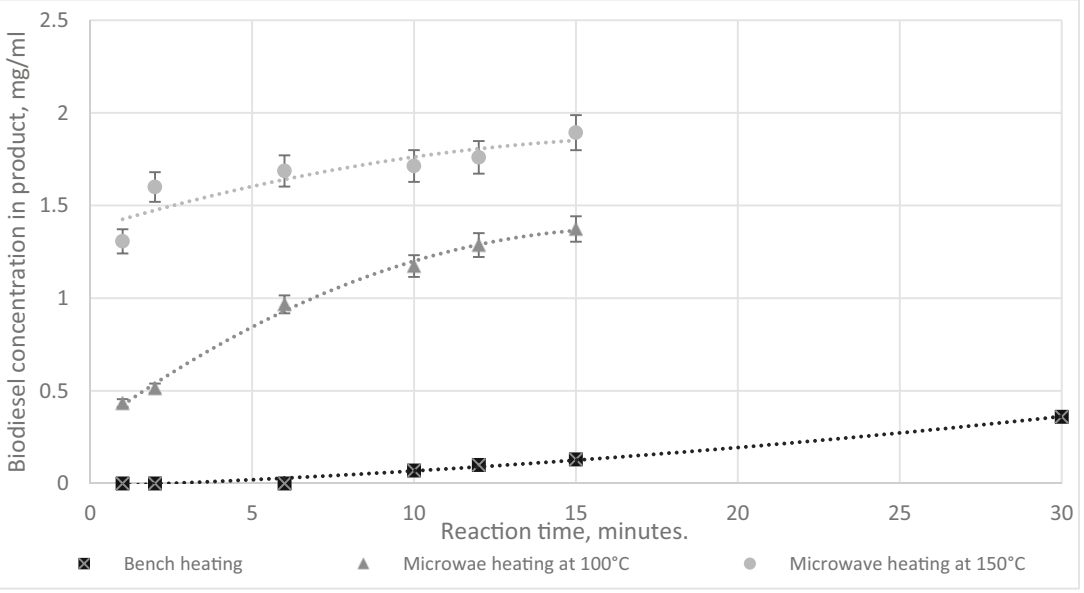

and third were performed in a sealed microwave vessel at 100 and $150{ }^{\circ} \mathrm{C}$ respectively. Figure 2 shows the FAME concentration after only $1 \mathrm{~min}$ of microwave heating is significantly higher than the 30-min FAME concentration from standard bench heating. The microwave heating was conducted at two temperatures in order to show the effect temperature has upon the esterification reaction taking place. As the reaction mixture contains $10 \mathrm{ml}$ of both methanol and heptane, this approaches the azeotropic ratio resulting in a boiling point of the benchtop reaction of around $59.1{ }^{\circ} \mathrm{C}$ at atmospheric pressure. The modest increase of reaction temperature used in the $100{ }^{\circ} \mathrm{C}$ microwave reaction gives a significantly higher concentration of FAME; the $150{ }^{\circ} \mathrm{C}$ reaction further increased the concentration of FAME produced in the 15-min reaction window. The additional $50{ }^{\circ} \mathrm{C}$ in reaction temperature between the two microwave reactions has a large effect on the resultant FAME concentration. This may be explained by the increase in pressure imparted upon the reaction by the heating of the solvent mixture far in excess of the azeotropic boiling point. As shown Fig. 2 as well as increasing the rate of extraction/esterification, the higher temperature microwave reactions also increased the total amount of FAME after the 15 -min heating period. To investigate how the increased temperature (and microwave power) can increase not only the rate but more importantly the yield of FAME through increased extraction of FA, SEM images of the POME solids before and after microwave treatment were taken. A marked increase in porosity demonstrated the appearance of holes in the POME solid structure. Figure 3 shows the structure of the POME solids under $\times 200$ magnification. The image shows the flaky nature of the substrate. Figure 4 shows two images of POME solids taken after the microwave reaction. The appearance of pores, holes and tears in the flakes of the POME solids could be responsible for the increased quantity of oil extracted from the POME solids in the microwave reactions by increasing the surface area of the solid as well as by breaking down the physical structure that could be retaining oils. The temperature of the microwave-heated reactions is controlled through the means of a PID loop that controls the microwave power delivered by the magnetron to the samples based on the setpoint temperature and the current sample temperature. In the case of the $150{ }^{\circ} \mathrm{C}$ microwave samples, not only was the temperature achieved by the microwave $50{ }^{\circ} \mathrm{C}$ hotter than the $100{ }^{\circ} \mathrm{C}$ reaction, the average incident power used to achieve and maintain this temperature would have been higher too. In addition, the reported temperature by the microwave control software can only refer to the bulk temperature inside of the vessel (due to the proxy measurement of temperature via a thermowell). Therefore, a value for the temperature of the individual constituents of the reaction vessel cannot be determined. It is a known
Fig. 3 SEM image of POME solids showing new holes and tears formed during microwave treatment at $150^{\circ} \mathrm{C}($ mag. $\times 1000)$
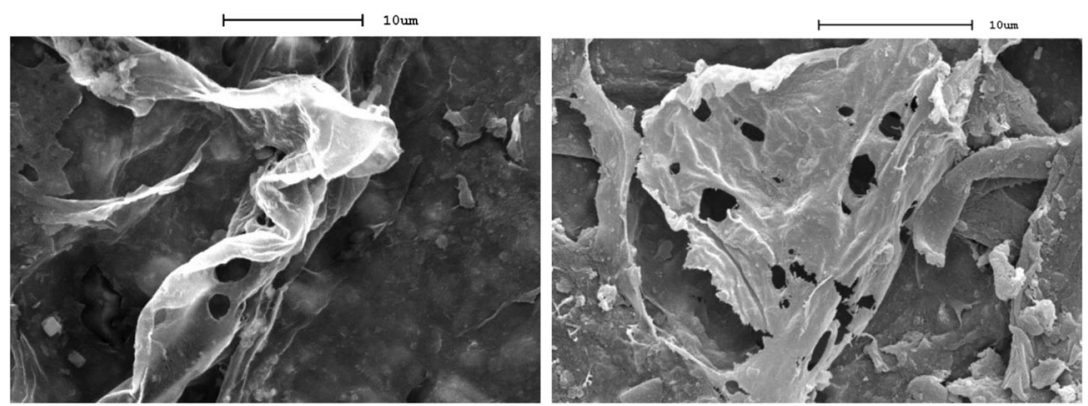


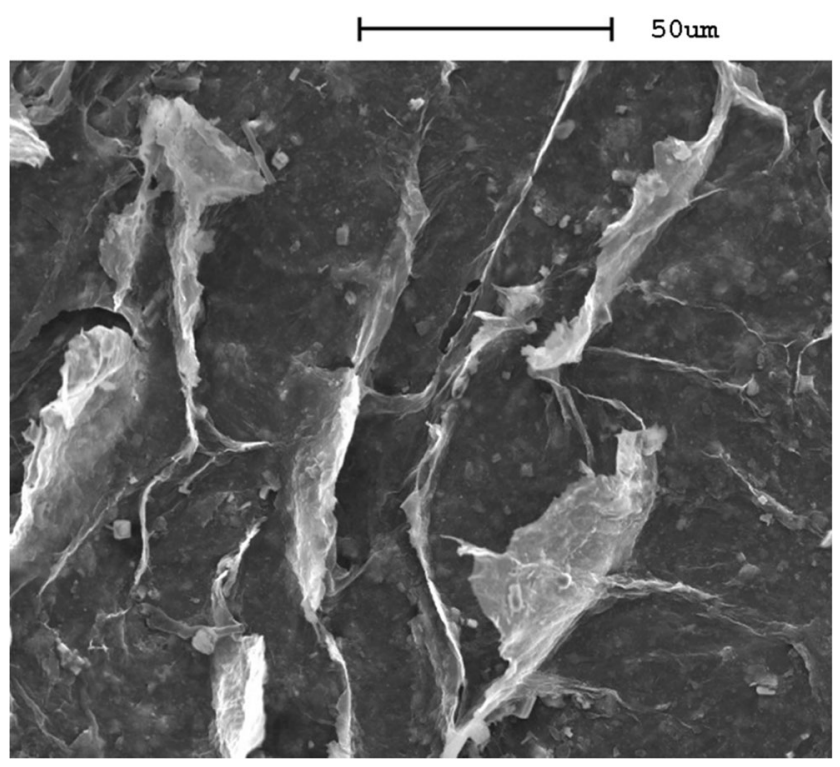

Fig. 4 SEM image of POME solid pre-microwave treatment (mag. $\times$ 200)

phenomenon that solid particles in microwaves may experience super-heating and form "hot-spots" as a function of very strong microwave absorbance in a localized area, and this could be used to explain how the modest increase in bulk microwave reaction temperature (from 100 to $150{ }^{\circ} \mathrm{C}$ ) could result in a significantly higher yield of oils liberated from the solid structure [29].

The higher incident power delivered by the microwave control software in the case of the hotter reaction could lead to an increased level of porosity developing as a result of the breakdown of the organic POME solids as a function of the increased level of superheating.

\subsection{CCD model and RSM analysis}

A central composite design (CCD) model was used to estimate the impact of methanol, $\mathrm{H}_{2} \mathrm{SO}_{4}$ concentration and stirring on the yield of biodiesel and the quantity of fatty acids extracted from POME. In this initial design, the temperature and time of reaction was fixed at $150{ }^{\circ} \mathrm{C}$ and $15 \mathrm{~min}$. The reason for this was to more accurately attribute the effects of methanol to oil ratio and acid concentration to the yield of biodiesel. The factors and their minimum and maximum values for the optimization are presented in Table 1.
In this investigation, both the concentration of biodiesel in the final product and the concentration of fatty acid were studied. The purpose of this is to investigate simultaneously the performance of fatty acid extraction from POME as well as the secondary step of esterification. This is done by back-calculating the concentration of fatty acid using the present concentration of the methyl ester and adding this to the value retuned from GC-MS of the unreacted (residual) fatty acid. The methanol to heptane volume ratio was varied between 0.1 and 0.5 , with a fixed $10-\mathrm{ml}$ volume of heptane being used for the extraction.

Table 2 shows the 28 reactions for the RSM study incorporating a CCD design. The effect of stirring, sulphuric acid concentration and methanol present in the reaction was investigated in order to study the extraction of FAs from the centrifuged POME matrix and the subsequent esterification of the extracted FAs to biodiesel. The experimental variables and responses from the CCD are given in Table 2. The highest 3 concentrations of FAME in the trial were from runs utilizing the maximum values for methanol content and $\mathrm{H}_{2} \mathrm{SO}_{4}$ concentration. In some runs there was an unquantifiable concentration of FAME in the sample post-reaction. The runs exhibiting zero FAME were almost exclusively characterized by the low $\mathrm{H}_{2} \mathrm{SO}_{4}$ concentration stressing the importance of acid in the esterification component of the extractionesterification process occurring in the microwave vessel. This trend is also observed in similar extraction/reaction experiments $[30,31]$. In terms of the fatty acid concentration, relating to the extraction component of the extractionesterification process, the highest concentrations of FA were also found from runs utilizing the maximum values for methanol:heptane volume ratio and $\mathrm{H}_{2} \mathrm{SO}_{4}$ concentration suggesting a role for both the acid and methanol in the initial extraction of the fatty acid from the POME matrix.

The fit statistics as shown in Table 3 above can be used to evaluate the applicability of the model for both the FA extraction and the subsequent esterification to create FAME. A high $R^{2}$ close to 1.00 for both models show that the fit of is good when compared with the experimental data. The modest difference between the predicted $R^{2}$ and adjusted $R^{2}$ could be used to indicate a block effect. However, the large value retuned for adequate precision means that the model is significantly representative of the data and can be used for the intended purpose to navigate the design space.

Table 1 Factors and ranges of experimental conditions used for the optimization investigation

\begin{tabular}{llllrrr}
\hline Factor & Name & Units & Type & Minimum & Maximum & Mean \\
\hline A & Methanol:Heptane vol ratio & Ratio & Numeric & 0.1000 & 0.5000 & 0.2929 \\
B & $\mathrm{H}_{2} \mathrm{SO}_{4}$ concentration & Molar & Numeric & 0.0010 & 0.0400 & 0.0198 \\
$\mathrm{C}$ & Stirring & $\%$ & Numeric & 20.00 & 100.00 & 58.57 \\
\hline
\end{tabular}


Table 2 Reaction variables and responses

\begin{tabular}{|c|c|c|c|c|c|}
\hline \multirow[b]{2}{*}{ Run } & \multicolumn{2}{|c|}{$\begin{array}{l}\text { Factor } 1 \quad \text { Factor } 2 \\
\text { Experimental conditions }\end{array}$} & Factor 3 & $\begin{array}{l}\text { Response } 1 \\
\text { Result }\end{array}$ & Response 2 \\
\hline & $\begin{array}{l}\text { A: Volume } \\
\text { of methanol } \\
\mathrm{ml}\end{array}$ & $\begin{array}{l}\mathrm{B}: \mathrm{H}_{2} \mathrm{SO}_{4} \\
\text { concentration } \\
\text { Molar }\end{array}$ & $\begin{array}{l}\text { C: Stirring } \\
\%\end{array}$ & $\begin{array}{l}\text { FAME } \\
\text { concentration } \\
\mathrm{mg} / \mathrm{ml}\end{array}$ & $\begin{array}{l}\text { FA concentration } \\
\text { (equivalent) } \\
\mathrm{mg} / \mathrm{ml}\end{array}$ \\
\hline 1 & 5 & 0.021 & 60 & 1.01 & 1.01 \\
\hline 2 & 5 & 0.040 & 20 & 1.09 & 1.05 \\
\hline 3 & 3 & 0.021 & 60 & 0.22 & 0.90 \\
\hline 4 & 3 & 0.021 & 60 & 0.20 & 0.86 \\
\hline 5 & 3 & 0.021 & 60 & 0.20 & 0.87 \\
\hline 6 & 1 & 0.021 & 60 & 0.00 & 0.79 \\
\hline 7 & 5 & 0.040 & 20 & 1.07 & 1.04 \\
\hline 8 & 5 & 0.001 & 20 & 0.00 & 0.68 \\
\hline 9 & 3 & 0.040 & 60 & 0.45 & 0.95 \\
\hline 10 & 3 & 0.001 & 60 & 0.00 & 0.81 \\
\hline 11 & 1 & 0.001 & 20 & 0.00 & 0.79 \\
\hline 12 & 3 & 0.021 & 60 & 0.21 & 0.88 \\
\hline 13 & 5 & 0.001 & 20 & 0.00 & 0.67 \\
\hline 14 & 1 & 0.040 & 100 & 0.08 & 0.83 \\
\hline 15 & 1 & 0.001 & 20 & 0.00 & 0.77 \\
\hline 16 & 1 & 0.040 & 100 & 0.07 & 0.83 \\
\hline 17 & 3 & 0.021 & 60 & 0.20 & 0.89 \\
\hline 18 & 1 & 0.001 & 100 & 0.00 & 0.74 \\
\hline 19 & 5 & 0.001 & 100 & 0.00 & 0.68 \\
\hline 20 & 3 & 0.021 & 60 & 0.21 & 0.88 \\
\hline 21 & 1 & 0.001 & 100 & 0.00 & 0.81 \\
\hline 22 & 5 & 0.001 & 100 & 0.09 & 0.74 \\
\hline 23 & 3 & 0.021 & 100 & 0.37 & 0.86 \\
\hline 24 & 3 & 0.021 & 60 & 0.21 & 0.91 \\
\hline 25 & 1 & 0.040 & 20 & 0.08 & 0.78 \\
\hline 26 & 1 & 0.040 & 20 & 0.05 & 0.80 \\
\hline 27 & 5 & 0.040 & 100 & 1.08 & 1.05 \\
\hline 28 & 3 & 0.021 & 20 & 0.65 & 0.91 \\
\hline
\end{tabular}

\subsection{Fatty acid extraction performance using RSM}

Table 4 is an excerpt from the ANOVA performed on the relationship between the model variables and the FA concentration and is used to determine the significance, or lack of significance of each model term. An $F$ value for the entire model of 40.62 implies significance, with a $0.01 \%$ chance this value being due to noise. $P$ values lower than 0.05 indicate model terms that are significant to the model. In this case, methanol quantity, A, and $\mathrm{H}_{2} \mathrm{SO}_{4}$ concentration, $\mathrm{B}$, are deemed to be significant. Stirring, C, with a $P$ value of 0.1998 is not deemed to have a significant effect upon the fatty acid concentration.

The 3D surface in Fig. 5 shows the concentration of extracted FA at all levels of $\mathrm{H}_{2} \mathrm{SO}_{4}$ concentration and methanol. As can be seen, FA concentration peaks when both the levels of $\mathrm{H}_{2} \mathrm{SO}_{4}$ concentration and methanol are at their maximum. The peak value of $1.05 \mathrm{mg} / \mathrm{ml}$ represents a 90.5\% yield of all available oil in POME when compared with the ISO method used for determination. This high value is obtained after only 15 min of extraction at $150{ }^{\circ} \mathrm{C}$ degrees and using only the centrifuged POME solids as opposed to the raw POME that the reference extraction was performed on.

The extraction of the FAs from the centrifuged POME solids was found to be dependent on both the concentration of $\mathrm{H}_{2} \mathrm{SO}_{4}$ and the volume of methanol present. As shown, even with all factors at their lowest the extracted FA concentration is still above $0.75 \mathrm{mg} / \mathrm{ml}$, over $64 \%$ of the oil extracted according to the reference ISO method; this must be attributed to the action of the high temperature of the microwave and the heptane that is also present

Table 3 Fit statistics for the model

\begin{tabular}{lcc}
\hline Parameter & FA concentration & FAME yield \\
\hline Std. Dev. & 0.0239 & 0.0991 \\
Mean & 0.8486 & 0.2693 \\
C.V. $(\%)$ & 2.82 & 36.81 \\
$R^{2}$ & 0.9742 & 0.9616 \\
Adjusted $R^{2}$ & 0.9502 & 0.9259 \\
Predicted $R^{2}$ & -0.1485 & -5.9939 \\
Adequate precision & 22.5356 & 17.6275 \\
\hline
\end{tabular}


Table 4 ANOVA table for fatty acid extraction (type III-partial)

\begin{tabular}{llrlrr}
\hline Source & Sum of squares & df & Mean square & $F$ value & $p$ value \\
\hline Model & 0.3016 & 13 & 0.0232 & 40.62 & $<0.0001$ \\
A-Methanol:Heptane vol ratio & 0.0237 & 1 & 0.0237 & 41.47 & $<0.0001$ \\
B-H2SO4 concentration & 0.0093 & 1 & 0.0093 & 16.35 & 0.0012 \\
C-Stirring & 0.0010 & 1 & 0.0010 & 1.81 & 0.1998 \\
\hline
\end{tabular}

in the vessel. The methanol content of the reaction has the strongest effect on the FA concentration suggesting some solubility of palmitic acid in the methanol or perhaps the methanol-heptane azeotrope that would be formed in reactions containing the $5 \mathrm{ml}$ of methanol. The next most significant factor was the $\mathrm{H}_{2} \mathrm{SO}_{4}$ concentration.

Whilst this was added ostensibly as an esterification catalyst (for the second step of the reaction) the effect of acid upon the POME solids may act to break down the solid structures allowing increased penetration of the extraction solvents, and subsequently, a higher amount of FA extracted. The least significant factor for FA extraction is the stirring which has a mildly detrimental effect on FA extraction. Figure 6 is a perturbation plot showing the effect of the three factors upon the FA concentration. The horizontal dimension of each line represents the range of values used in the experiments. Line A represents effect of the methanol volume on the extraction and ranges from 1 to $5 \mathrm{ml}$, line $\mathrm{B}$ represents the effect of $\mathrm{H}_{2} \mathrm{SO}_{4}$ concentration upon the extraction when varied from 0.001 to $0.04 \mathrm{mg} / \mathrm{ml}$ and line $\mathrm{C}$ represents the stirring rate used in the microwave reactor as a unitless value and was adjusted between 20 and $100 \%$ of the maximum. As can be seen, A is the steepest gradient showing that the amount of methanol is most important to this initial extraction step.

\subsection{Biodiesel production performance using RSM}

The esterification of the extracted palmitic acid to methyl palmitate (FAME) was also analysed through RSM as the final yield of biodiesel from the POME is the most important factor in this study overall. As shown in Table 5, and in common with the FA extraction model, methanol quantity (A) and $\mathrm{H}_{2} \mathrm{SO}_{4}$

concentration (B) are deemed to be significant. Stirring, C, with a $P$ value of 0.0656 , is not deemed to have a significant effect upon the FAME concentration. Figure 7 is a $3 \mathrm{D}$ surface showing that a high yield of biodiesel is only produced under conditions with the highest amount of acid and methanol. However, under these circumstances the peak yield of biodiesel when compared with the available FAs in raw POME is $89 \%$. Whilst conditions used for the reaction were somewhat harsh and a high amount of methanol used, this can be recovered from the reaction mixture in a simple way through
Fig. 5 Effect of $\mathrm{H}_{2} \mathrm{SO}_{4}$ concentration and methanol on the extracted FA concentration. Colour represents FAME concentration from 0 (blue) to $1.05 \mathrm{mg} / \mathrm{ml}$ (red)
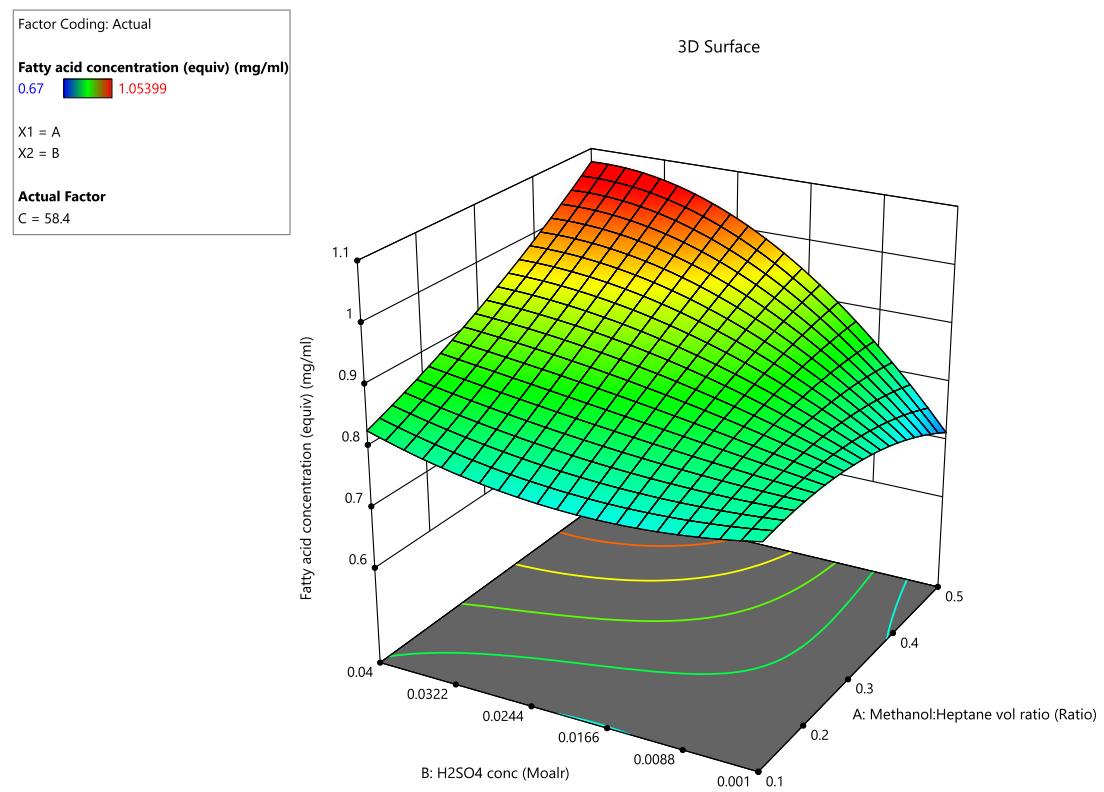


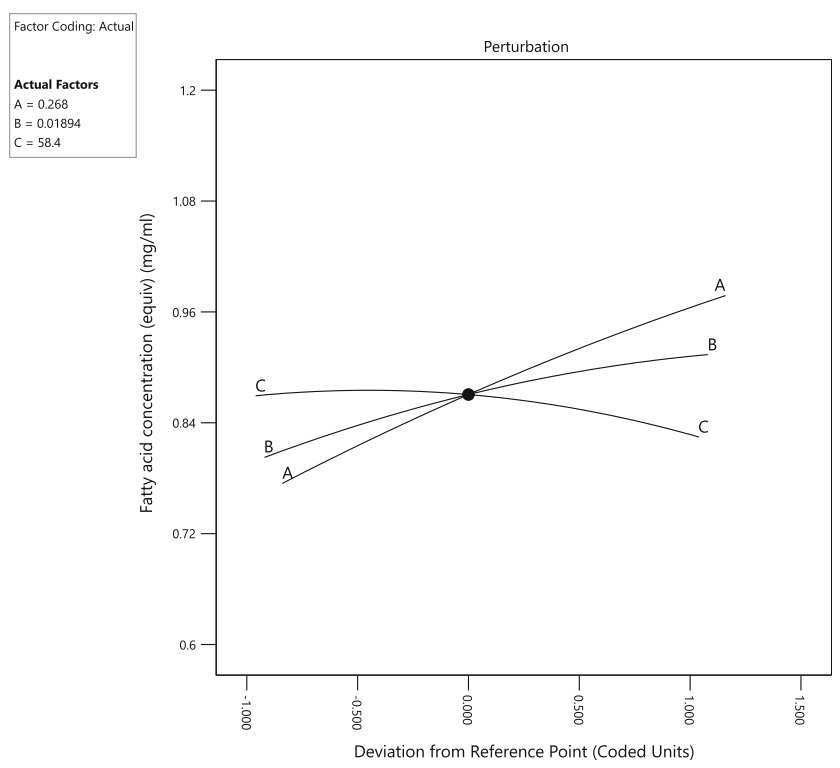

Fig. 6 Perturbation plot showing the influence of all factors on the FA concentration

distillation. The amount of methanol used could be reduced if the POME solids were dried prior to reaction however with only mild centrifugation this method can achieve a high biodiesel yield with only a 15 -min reaction time

Further study into optimizing the reaction with respect to temperature and reaction time could yield even more impressive results for the exploitation of this difficult feedstock. The perturbation plot, Fig. 8, shows the magnitude of the contributions of the factors to the final concentration of FAME in the product. As shown, the most significant factor to biodiesel concentration is the methanol content in the reaction. This can be explained by the dynamic equilibrium present in the esterification reaction between reactants and products as shown in Fig. 9. An excess of methanol will help to drive the equilibrium towards the biodiesel, this is especially important due to the residual water present in the centrifuged POME that will work in favour of the reverse reaction. The effect of $\mathrm{H}_{2} \mathrm{SO}_{4}$ concentration on the yield of biodiesel is the second most significant factor in this series of reactions. As the esterification catalyst it would be expected that the reaction responds well to an increase in acid concentration. In addition, $\mathrm{H}_{2} \mathrm{SO}_{4}$ also acts to dehydrate the reaction, diminishing the disruptive effect of residual water on the dynamic equilibrium formed between the biodiesel product and reactants in the reaction. As seen with the FA extraction, stirring had a modest albeit negative effect upon the final biodiesel concentration. Possible reasons for this could be that the increased agitation causes mixing of the organic and aqueous layer leading to increased contact between FAME molecules and water present in the reaction leading to acid hydrolysis of the product.

\subsection{RSM insight in to maximizing biodiesel yield}

A useful output from a statistical model is the ability to attribute relative (and actual) contributions from each factor to deconvolute the relationships and possible interactions between factors in order to optimize the reaction conditions towards minimizing energy use or amount of materials used for example. Table 6 is a table of factor coefficients that estimate the contributions from not only the individual factors but the interactions between factors (compound factors) represented by the multiple letter entries. A positive value for the estimated coefficient represents a positive relationship between increasing the value of the factor and a resultant increase in response value. For example, factor B, $\mathrm{H}_{2} \mathrm{SO}_{4}$ concentration has a positive coefficient, meaning that an increase in $\mathrm{H}_{2} \mathrm{SO}_{4}$ concentration will give a higher biodiesel yield. Whereas in factor $\mathrm{C}$, stirring has a negative coefficient, meaning that in order to maximize the response, stirring should be minimized.

\section{Actual reaction equation}

Equation 1 can be used to predict the actual methyl ester concentration from the model when variables are entered using the same units as used in the model.
Table 5 ANOVA table for biodiesel esterification [Type III Partial]

\begin{tabular}{llrlrr}
\hline Source & Sum of squares & df & Mean square & $F$ value & $p$ value \\
\hline Model & 3.44 & 13 & 0.2648 & 26.96 & $<0.0001$ \\
A-Methanol:Heptane vol ratio & 0.5101 & 1 & 0.5101 & 51.92 & $<0.0001$ \\
B- $_{2} \mathrm{SO}_{4}$ concentration & 0.1012 & 1 & 0.1012 & 10.31 & 0.0063 \\
C-Stirring & 0.0392 & 1 & 0.0392 & 3.99 & 0.0656 \\
\hline
\end{tabular}


Fig. 7 Effect of $\mathrm{H}_{2} \mathrm{SO}_{4}$ concentration and methanol on the FAME concentration. Colour represents FAME concentration from 0 (blue) to $1.09 \mathrm{mg} / \mathrm{ml}$ (red)

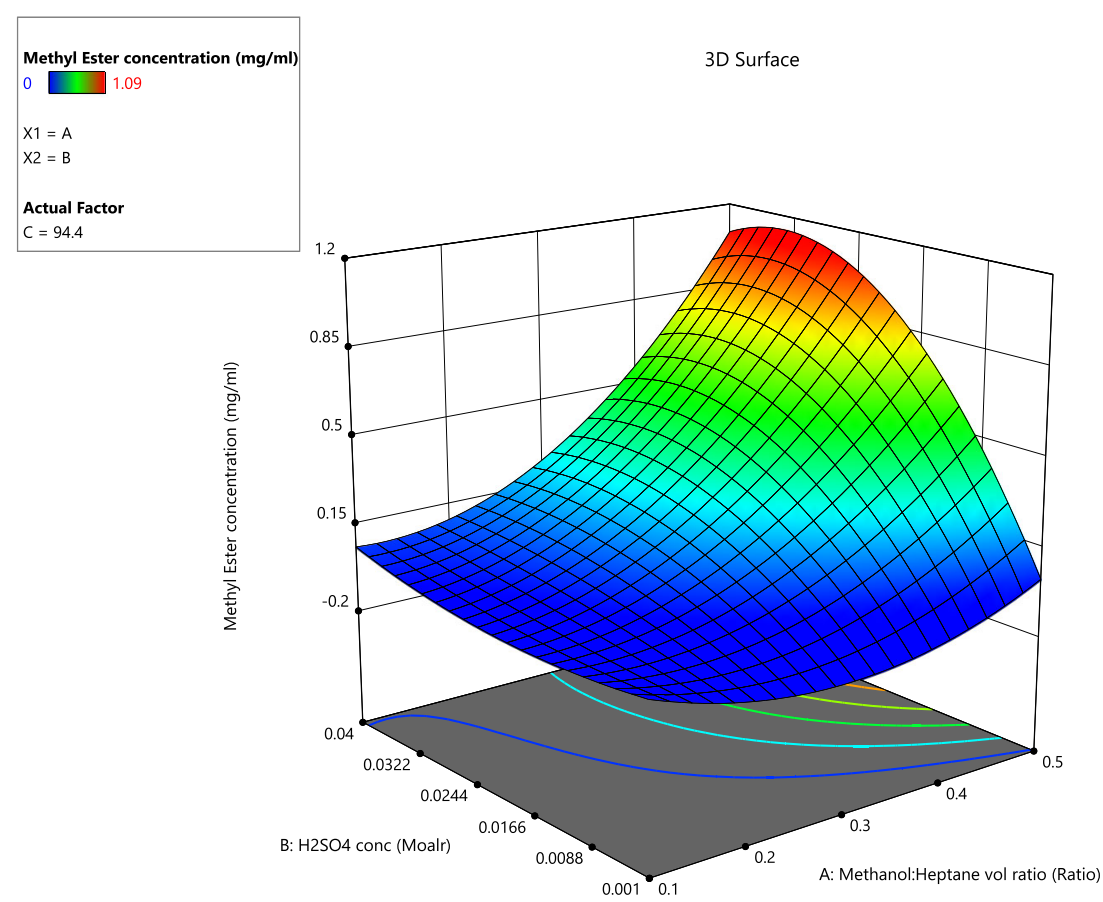

Predicted methyl ester concentration $=-0.050599+(2.51617 \mathrm{~A})--(21.66933 \mathrm{~B})--(0.003557 \mathrm{C})+$ $(152.49966 \mathrm{AB})-(0.054369 \mathrm{AC})+(0.006367 \mathrm{BC})-\left(4.56470 \mathrm{~A}^{2}\right)+\left(499.33209 \mathrm{~B}^{2}\right)+\left(0.000067 \mathrm{C}^{2}\right)-$ $(0.031617 \mathrm{ABC})+\left(75.40736 \mathrm{~A}^{2} \mathrm{~B}\right)+\left(0.093011 \mathrm{~A}^{2} \mathrm{C}\right)-\left(3220.69398 \mathrm{AB}^{2}\right)$

Where : $\mathrm{A}=$ Methanol : Heptane volume ratio

$\mathrm{B}=\mathrm{H} 2 \mathrm{SO} 4$ Concentration

$\mathrm{C}=$ Stirring rate

Equation 1 Predicted methyl ester concentration calculated from model terms

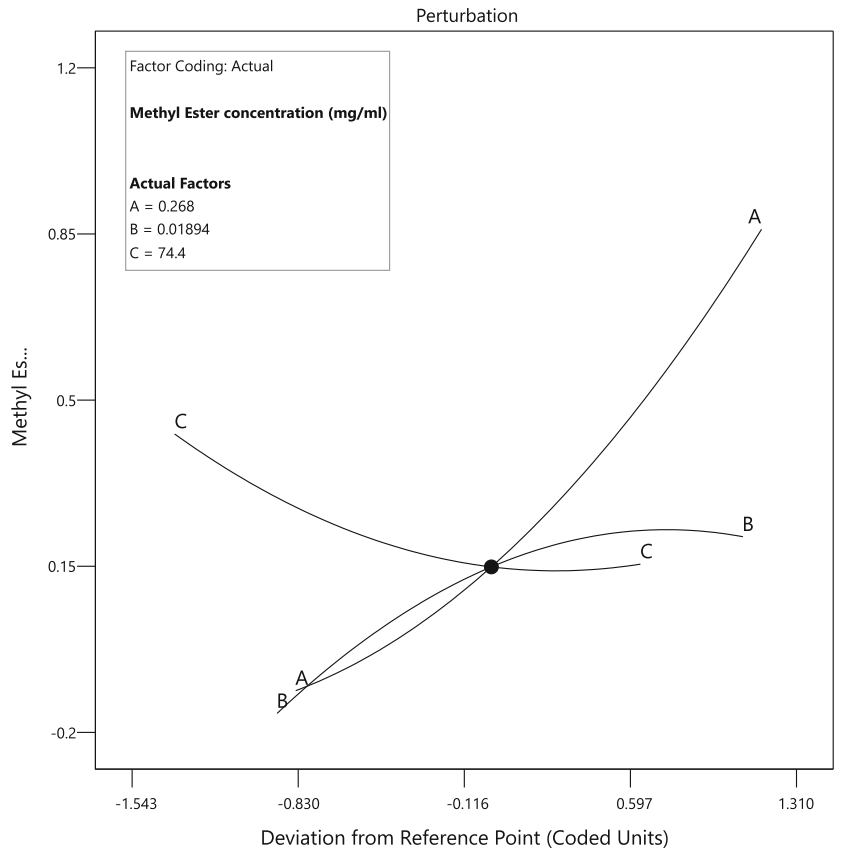

Fig. 8 Perturbation plot showing the influence of all factors on the biodiesel concentration

\section{Conclusion}

This study has shown the potential for conversion of fatty acids from POME into biodiesel. In keeping with circular economy principles, this provides a route to extracting further value from an industrial residue. Once implemented, this approach would provide a financial incentive to mill operators to capture and manage POME without leakages to the environment. It also offers an additional relatively high value output in the context of rural economies in a developing country. FAs were extracted and esterified in a single reaction vessel from centrifuged POME and converted to biodiesel with a peak yield of $89 \%$ at $150{ }^{\circ} \mathrm{C}$ and a reaction time of $15 \mathrm{~min}$. This high efficiency reaction could provide a method to obtain large quantities of biodiesel from a waste material, reducing

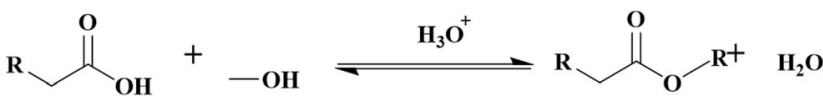
Fatty Acid Methanol Ester product

Fig. 9 Equilibrium formed between reactants and products in the production of esters 
Table 6 Factor coefficients for biodiesel esterification yield

\begin{tabular}{lccccc}
\hline Factor & Coefficient estimate & df & Standard error & $95 \%$ CI low & $95 \%$ CI high \\
\hline Intercept & 0.2782 & 1 & 0.0321 & 0.2094 & 0.3470 \\
A-Methanol:Heptane vol ratio & 0.5050 & 1 & 0.0701 & 0.3547 & 0.6553 \\
B-H2SO4 concentration & 0.2250 & 1 & 0.0701 & 0.0747 & 0.3753 \\
C-Stirring & -0.1400 & 1 & 0.0701 & -0.2903 & 0.0103 \\
$\mathrm{AB}$ & 0.2488 & 1 & 0.0263 & 0.1925 & 0.3052 \\
$\mathrm{AC}$ & 0.0063 & 1 & 0.0263 & -0.0500 & 0.0627 \\
$\mathrm{BC}$ & -0.0024 & 1 & 0.0263 & -0.0588 & 0.0539 \\
$\mathrm{~A}^{2}$ & 0.1025 & 1 & 0.0590 & -0.0241 & 0.2291 \\
$\mathrm{~B}^{2}$ & -0.1775 & 1 & 0.0590 & -0.3041 & -0.0509 \\
$\mathrm{C}^{2}$ & 0.1075 & 1 & 0.0590 & -0.0191 & 0.2341 \\
$\mathrm{ABC}$ & -0.0049 & 1 & 0.0263 & -0.0613 & 0.0514 \\
$\mathrm{~A}^{2} \mathrm{~B}$ & 0.0588 & 1 & 0.0748 & -0.1017 & 0.2194 \\
$\mathrm{~A}^{2} \mathrm{C}$ & 0.1488 & 1 & 0.0748 & -0.0117 & 0.3094 \\
$\mathrm{AB}$ & -0.2449 & 1 & 0.0748 & -0.4055 & -0.0844 \\
\hline
\end{tabular}

the environmental impact of the free FA component of POME. Further studies could include the scale-up of the batch-based microwave technique to a larger flow system more suited to the continuous nature of POME production at palm oil mills.

Funding information The authors received financial support from The Newton Fund (British Council Institutional Links Grant, with the University of Malaysia Sabah Institutional Links Grant (Application ID 172702808) used to obtain representative samples of POME from Sabah, Malaysia.

Open Access This article is licensed under a Creative Commons Attribution 4.0 International License, which permits use, sharing, adaptation, distribution and reproduction in any medium or format, as long as you give appropriate credit to the original author(s) and the source, provide a link to the Creative Commons licence, and indicate if changes were made. The images or other third party material in this article are included in the article's Creative Commons licence, unless indicated otherwise in a credit line to the material. If material is not included in the article's Creative Commons licence and your intended use is not permitted by statutory regulation or exceeds the permitted use, you will need to obtain permission directly from the copyright holder. To view a copy of this licence, visit http://creativecommons.org/licenses/by/4.0/.

\section{References}

1. European Commission (2015) Closing the loop - an EU action plan for the circular economy. European Commission, Brussels

2. Schroeder P, Anggraeni K, Weber U (2019) The relevance of circular economy practices to the sustainable development goals. J Ind Ecol 23(1):77-95

3. World Circular Economy Forum (2018) WCEF2018 report. In: World Circular Economy Forum. Sitra, Yokohama

4. Ashton W, Baas L, Baumann H, Bi J, Boons F, Branson R, Brullot S, Costa I, Davis C, Deutz P, Gibbs D, Eklund M, Hu L, Isenmann R, Korevaar G, Liu L, Lowitt P, Lei Y, Lyons D, Zhang B (2015)
Comparing industrial symbiosis in Europe: towards a conceptual framework and research methodology. Int Perspect Ind Ecol https:// doi.org/10.4337/9781781003572.00013

5. Carter C, Finley W, Fry J, Jackson D, Willis L (2007) Palm oil markets and future supply. Eur J Lipid Sci Technol 109(4):307-314

6. Shuit SH, Tan KT, Lee KT, Kamaruddin AH (2009) Oil palm biomass as a sustainable energy source: a Malaysian case study. Energy 34(9):1225-1235

7. Kurnia JC, Jangam SV, Akhtar S, Sasmito AP, Mujumdar AS (2016) Advances in biofuel production from oil palm and palm oil processing wastes: a review. Biofuel Res J 3(1):332-346

8. Poh PE, Yong W-J, Chong MF (2010) Palm oil mill effluent (POME) characteristic in high crop season and the applicability of high-rate anaerobic bioreactors for the treatment of POME. Ind Eng Chem Res 49(22):11732-11740

9. Latif Ahmad A, Ismail S, Bhatia S (2003) Water recycling from palm oil mill effluent (POME) using membrane technology. Desalination 157(1-3):87-95

10. Hariz HB, Takriff MS (2017) Palm oil mill effluent treatment and $\mathrm{CO}_{2}$ sequestration by using microalgae - sustainable strategies for environmental protection. Environ Sci Pollut Res 24(25):20209 20240

11. Chin KK, Lee SW, Mohammad HH (1996) A study of palm oil mill effluent treatment using a pond system. Water Sci Technol 34(11): $119-123$

12. Lam MK, Lee KT (2011) Renewable and sustainable bioenergies production from palm oil mill effluent (POME): win-win strategies toward better environmental protection. Biotechnol Adv 29(1): 124-141

13. Wu TY, Mohammad AW, Jahim JM, Anuar N (2010) Pollution control technologies for the treatment of palm oil mill effluent (POME) through end-of-pipe processes. J Environ Manag 91(7): 1467-1490

14. Borja R, Banks CJ (1995) Comparison of an anaerobic filter and an anaerobic fluidized bed reactor treating palm oil mill effluent. Process Biochem 30(6):511-521

15. Singh G, Majlis Penanam-Penanam Kelapa Sawit, M (1999) Oil palm and the environment: a Malaysian perspective. Malaysian Oil Palm Grower's Council: [Kuala Lumpur]

16. Moser BR (2009) Biodiesel production, properties, and feedstocks. In Vitro Cell Dev Biol Plant 45(3):229-266 
17. Lam MK, Lee KT, Mohamed AR (2010) Homogeneous, heterogeneous and enzymatic catalysis for transesterification of high free fatty acid oil (waste cooking oil) to biodiesel: a review. Biotechnol Adv 28(4):500-518

18. Silva Filho SC d, Miranda AC, Silva TAF, Calarge FA, Souza RR d, Santana JCC, Tambourgi EB (2018) Environmental and technoeconomic considerations on biodiesel production from waste frying oil in São Paulo city. J Clean Prod 183:1034-1042

19. Hajjari M, Tabatabaei M, Aghbashlo M, Ghanavati H (2017) A review on the prospects of sustainable biodiesel production: a global scenario with an emphasis on waste-oil biodiesel utilization. Renew Sust Energ Rev 72:445-464

20. Kulkarni MG, Dalai AK (2006) Waste cooking OilAn economical source for biodiesel: a review. Ind Eng Chem Res 45(9):2901-2913

21. Dorado MP, Ballesteros E, de Almeida JA, Schellert C, P. Löhrlein H, Krause R (2002) An alkali-catalyzed transesterification process for high free fatty acid waste oils. Trans ASAE 45(3):525

22. Suwanno S, Rakkan T, Yunu T, Paichid N, Kimtun P, Prasertsan P, Sangkharak K (2017) The production of biodiesel using residual oil from palm oil mill effluent and crude lipase from oil palm fruit as an alternative substrate and catalyst. Fuel 195:82-87

23. Hossain A, Nyah J, Ahmad A, Omran A, Davies P (2016) Experimental investigation of the fuel properties of glidfuel, palm oil mill effluent biodiesel and blends. In: KohseHoinghaus K, Ranzi E (eds) 2nd International Conference on Biomass, vol 50. Aidic Servizi Srl, Milano, pp 361-366

24. Gedye R, Smith F, Westaway K, Ali H, Baldisera L, Laberge L, Rousell J (1986) The use of microwave-ovens for rapid organicsynthesis. Tetrahedron Lett 27(3):279-282
25. Bren M, Janežič D, Bren U (2010) Microwave catalysis revisited: an analytical solution. J Phys Chem A 114(12):4197-4202

26. Ganzler K, Szinai I, Salgó A (1990) Effective sample preparation method for extracting biologically active compounds from different matrices by a microwave technique. J Chromatogr A 520:257-262

27. Béatrice K, Philippe C (2002) Recent extraction techniques for natural products: microwave-assisted extraction and pressurised solvent extraction. Phytochem Anal 13(2):105-113

28. Vinatoru M, Mason TJ, Calinescu I (2017) Ultrasonically assisted extraction (UAE) and microwave assisted extraction (MAE) of functional compounds from plant materials. TrAC Trends Anal Chem 97:159-178

29. Berlan J (1995) Microwaves in chemistry: another way of heating reaction mixtures. Radiat Phys Chem 45(4):581-589

30. Lappalainen K, Vogeler N, Kärkkäinen J, Dong Y, Niemelä M, Rusanen A, Ruotsalainen AL, Wäli P, Markkola A, Lassi U (2018) Microwave-assisted conversion of novel biomass materials into levulinic acid. Biomass Convers Biorefinery 8(4):965-970

31. Zhu ZY, Liu YB, Yang XL, McQueen-Mason SJ, Gomez LD, Macquarrie DJ (2020) Comparative evaluation of microwaveassisted acid, alkaline, and inorganic salt pretreatments of sugarcane bagasse for sugar recovery. Biomass Convers Biorefinery 13 https://doi.org/10.1007/s13399-020-00680-7

Publisher's Note Springer Nature remains neutral with regard to jurisdictional claims in published maps and institutional affiliations. 